\title{
Do children derive exact meanings pragmatically? Evidence from a dual morphology language
}

\author{
Franc Marušič, Rok Žaucer, Amanda Saksida, Jessica Sullivan, Dimitrios Skordos, Yiqiao \\ Wang, \& David Barner
}

\begin{abstract}
Number words allow us to describe exact quantities like sixty-three and (exactly) one. How do we derive exact interpretations? By some views, these words are lexically exact, and are therefore unlike other grammatical forms in language. Other theories, however, argue that numbers are not special and that their exact interpretation arises from pragmatic enrichment, rather than lexically. For example, the word one may gain its exact interpretation because the presence of the immediate successor two licenses the pragmatic inference that one implies "one, and not two". To investigate the possible role of pragmatic enrichment in the development of exact representations, we looked outside the test case of number to grammatical morphological markers of quantity. In particular, we asked whether children can derive an exact interpretation of singular noun phrases (e.g., "a button") when their language features an immediate "successor" that encodes sets of two. To do this, we used a series of tasks to compare Englishspeaking children who have only singular and plural morphology to Slovenian-speaking children who have singular and plural forms, but also dual morphology, that is used when describing sets of two. Replicating previous work, we found that English-speaking preschoolers failed to enrich their interpretation of the singular and did not treat it as exact. New to the present study, we found that 4- and 5-year-old Slovenian-speakers who comprehended the dual treated the singular form as exact, while younger Slovenian children who were still learning the dual did not, providing evidence that young children may derive exact meanings pragmatically.
\end{abstract}

Keywords: Acquisition of quantity expressions, acquisition of exactness, pragmatics of grammatical number, inferences on quantity, dual, Slovenian

\section{Introduction}

One of the most powerful properties of number language is that it can represent exact quantities via words like two and fifty-seven. ${ }^{1}$ Even before formal schooling, children in numerate cultures begin to acquire exact number word meanings, and can count and give small sets of objects. For example, when asked to give an experimenter two fish, children who understand the meaning of two give exactly two fish, but not one or three (Wynn, 1990, 1992; Carey, 2009). While the fact that numbers can take on exact interpretations is not controversial, the source of these exact interpretations - both in language processing and in acquisition - is disputed. The present study

1 In this paper we use italics when referring to symbolic forms of numbers such as number words. Two and fiftyseven thus stand for the number words denoting 2 and 57 in the language under discussion. 
explores this issue by asking whether at least some exact interpretations might arise in language acquisition via pragmatic strengthening.

Empirically, it is relatively uncontroversial that verbal numerals like twelve can take on either exact, (1a), lower-bounded, (1b), or upper-bounded meanings, (1c), in context. What's disputed, however, is how these meanings arise, and whether exact meanings are stored lexically or derived via additional computations.

(1) a. Each student in the class read twelve books this year.

b. Each student in the class must read twelve books this year.

c. Each student is allowed to read twelve books this year.

By some accounts, adult speakers have lexically exact meanings for number words, such that the meaning of the numeral twelve is “exactly 12" (Breheny, 2008; Carston, 1998; Huang, Spelke, \& Snedeker, 2013; Koenig, 1991; Saddock, 1984; Scharten, 1997). However, multiple alternative possibilities also exist, ranging from the view that numerals receive a lower-bounded meaning by default (Horn, 1972; van Rooij and Schulz, 2004; Panizza, Chierchia, Clifton, 2009), that they are lexically ambiguous, and feature exact, lower-bounded, and upper-bounded meanings which are selected via grammatical or contextual mechanisms (Geurts, 2006; Levinson, 2000; Spector, 2013), or that these different meanings are derived pragmatically from a sense that is "weaker" than any of them (Carston, 1988, 1998). Also, within this range of basic options many formal variants have been proposed, although a complete discussion of the differences between these models extends beyond the scope of this paper (Brasoveanu, 2013; Fox \& Hackl, 2007; Kennedy, 2015; Nouwen, 2010; Rett, 2014; Schwarz, Buccola, \& Hamilton, 2012).

On Neo-Gricean accounts, expressions like (1a) receive an exact interpretation via a process of pragmatic reasoning involving scalar implicature, wherein the original expression is interpreted relative to stronger, alternative expressions that can be generated by replacing the scalar item twelve with lexical alternatives like thirteen, as in (2):

(2) a. Upon hearing "Each student read twelve books", assume that the speaker believes this utterance to be true, and therefore that each student read at least 12 books.

b. Note that the speaker could have uttered a range of stronger alternative utterances including, e.g., "Each student read thirteen books".

c. Infer that, since the speaker did not utter those stronger utterances, they must not believe them to be true.

d. Assume that the speaker knows how many books each student read, and therefore conclude that they believe the stronger alternatives to be false - e.g., that it is not the case that each student read 13, 14, 15, or more books.

This form of inference depends on the existence of a scale, made up of scalar alternatives that include the set of verbal numerals. Also, although in this instance the inference is described 
in the context of a Neo-Gricean "at least" semantics, analogs to this form of inference are available to alternative theories that adopt underspecification and ambiguity, or that assume grammatical mechanisms of “exhaustification” rather than Gricean reasoning about speaker states (e.g., Chierchia, Fox, \& Spector, 2012; Fox, 2007), where the term exhaustification also refers to the negation of stronger alternatives when interpreting a sentence. Common to inferential accounts is the idea that exact meanings arise from a process of contrasting the basic meaning of an utterance with alternative utterances that are derived by replacing the numeral with a stronger alternative.

The starting point for this work is to note that, in the case of verbal numerals, it is difficult to evaluate the relative contributions of lexical representations and the pragmatic negation of alternatives, since it is generally the case that speakers who have knowledge of a number word like one also have knowledge of its successor (i.e., two) and many other numbers, too. For this reason, previous studies have argued that a more fruitful strategy is to investigate language users who do not yet have complete adult competence, like children. For example, earlier studies (e.g., Papafragou \& Musolino, 2003; Huang, Spelke, \& Snedeker, 2013) reasoned that children might provide a particularly strong test of whether the exact interpretation of numerals depends on lexical specification or pragmatic processes since (1) children failed at early-reported tests of scalar implicature (e.g., Noveck, 2001; Smith, 1980), and (2) early studies of number word learning suggested that children acquire numeral meanings one at a time in sequence, such that children who have learned, e.g., the meaning of one, initially lack a meaning for its immediate successor two (Wynn, 1990, 1992; Huang, Spelke, \& Snedeker, 2013; Le Corre \& Carey, 2007). Given these two findings, studies such as Huang et al. (2013) reasoned that children's ability to acquire exact number word meanings as early as 2 years of age could not be explained by implicature, because many children who have acquired an exact meaning for one lack access to the meaning of its successor, and because very generally they lack the ability to compute scalar implicatures.

However, two sets of findings have challenged this line of reasoning. First, many studies have now shown that young children can compute implicatures when stronger scalar alternatives are made contextually available, and that early failures were therefore due to children's inability to access scalar alternatives, not a general pragmatic deficit (e.g., Barner, Brooks, \& Bale, 2011; Barner, Hochstein, Rubenson, \& Bale, 2018; Chierchia, Crain, Guasti, Gualmini, Meroni, 2001; Foppolo, Guasti, \& Chierchia, 2012; Hochstein, Bale, Fox, \& Barner, 2016; Miller, Schmidt, Chang, \& Munn, 2005; Long, Shukla \& Rubio-Fernandez, 2020; Pagliarini, Bill, Romoli, Tieu, \& Crain, 2018; Papafragou \& Tantalou, 2004; Singh, Wexler, Astle-Rahim, Kamawar, \& Fox, 2016; Skordos \& Papafragou, 2016; Stiller, Goodman, \& Frank, 2015). For example, in one study, by Skordos and Papafragou (2016), children failed to compute some vs. "all scalar implicatures under conditions similar to earlier studies, but succeeded when scalar alternatives were made more available. In particular, when children received test trials involving some first e.g., "Some of the animals have a scarf", most children judged such utterances to be acceptable even when all was true - e.g., "All of the animals had a scarf”. However, when they first received a series of trials testing all - e.g. "All of the animals have a scarf”, children later computed scalar 
implicatures for some trials at adult-like levels, suggesting that access to stronger alternatives facilitated the calculation of implicatures. Given that 2-year-old children begin the process of number word learning by memorizing a rote list of numerals, these results lend plausibility that children might spontaneously access numeral alternatives and compute implicatures early in acquisition.

Second, several studies have now reported that common tests of number word learning underestimate children's knowledge in a way that specifically impacts claims regarding the origin of exact meanings. For example, in Wynn's Give-a-Number task, children are asked to give the experimenter different numbers of things ranging from 1-10, and are then assigned a "knower level" indicating the highest number word they comprehend. Typically, studies find that children go through one-knower, two-knower, three-knower, and sometimes four-knower stages, learning each new word gradually and in sequence, until finally they learn to use counting to construct sets, and perform well for larger numbers too (i.e., five, six, seven, etc.). Critically, Wynn's test classifies children as one-knowers if they can successfully give 1 item when asked for one on 2 out of 3 trials, while also not giving 1 item in response to larger numbers. This second criterion is critical, because it requires that children know that two is lower bounded and cannot refer to sets of 1, which is not a property of a completely novel and unknown word (e.g., "blicket”; Wynn, 1992), or of other quantificational expressions that aren't on a scale with numerals (e.g., some). Consequently, any child who treats a number word like one exactly must also know something about its successor (in this case two), whether by inference or because they've acquired its lexical meaning. In favor of the second possibility, Barner and Bachrach found that children who are classified as n-knowers (e.g., one-knowers, two-knowers, or threeknowers) often perform above chance on $n+1$ despite not treating it as upper bounded and exact, a result that has now been replicated by at least three other studies (Gunderson, Spaepen, \& Levine, 2015; Wagner, Chu, \& Barner, 2019; O’Rear, McNeil, \& Kirkland, 2020). Given this, it is difficult to find children who have an exact meaning of a number word but completely lack knowledge of any larger numbers, making it hard to test whether exact meanings can be learned in absence of stronger alternatives. More generally, children appear to know more about both number words and implicature than supposed by earlier studies in the literature, suggesting that evidence from number word learning cannot currently rule out a role for pragmatic processes in the origin of exact number word meanings.

Although it is difficult to find language users who comprehend a number word like one without knowledge of its successor two, other morphological expressions of number exhibit precisely this kind of variability cross-linguistically and, as we show in the present study, in language acquisition. In particular, languages differ with respect to whether singular forms like “a book”, typically used to express singleton sets, have immediate "successors” that express doubleton sets in the form of dual morphology (paralleling the number two as the immediate successor of the number one). Whereas English lacks dual forms, various other languages do have a dual, including Central Slovenian, the language that we investigate here. 
Many languages, including English, feature a grammatical distinction between singular and plural forms, as in (3). Interestingly, the singular/plural distinction does not always lead to the same pattern of exhaustification as is found with verbal numerals.
a. Each student read a book.
b. Each student read some books.

A first intuition regarding the utterance in (3a) is that it receives an "at least" interpretation, and therefore is true so long as each student read at least one book, including scenarios in which each read two or three. Also, it's tempting to conclude that the plural NP "some books" in (3b) generates a lower-bounded meaning, such that each student must have read at least two books and possibly more. Interestingly, for reasons that aren't entirely resolved, the existence of (3b) as a candidate alternative to (3a) does not lead automatically to the exhaustification of the singular NP “a book” (i.e., Each student read exactly one book). That is, the singular/plural distinction does not amount to a consistent distinction between one and more than one (see Mathieu, 2014; Bale, 2009; Bale, Gagnon, \& Khanjian, 2011; Krifka, 1989; Sauerland, 2003; Sauerland, Andersen, \& Yatsushiro, 2005; Spector, 2007; Zweig, 2009). Instead, singular NPs like the one in (3a) often remain unexhaustified and lower bounded in contexts that typically generate exact meanings for numerals, like in (1a). As evidence for this, a question like, "Do you have a child?" can be answered in the affirmative with either a singular "Yes, I have one” or plural form "Yes, I have three”. Also, importantly, utterances like the ones in (4a) and (4b) are not simple opposites; whereas (4a) implies that the speaker has more than one child, the utterance in (4b) does not mean "it is not the case that I have more than one child". Instead, it means that the speaker has no children at all.
a. I have children.
b. I don't have children.

However, in other contexts the singular carries a relatively strong implication of exactness, as in (5a), where the choice of the singular implies that the speaker does not have more than one child. Likewise, (5b) strongly implies that the speaker has more than one child.

(5) a. I can't go out tonight; I have a child.

b. I can't go out tonight; I have children.

Together, these facts suggest that the plural form alone may not offer a straightforward stronger alternative to the singular, and that, perhaps because of this, exact meanings of the singular are 
more elusive and context-specific than in the case of numerals, where a clear ordering relation exists between the words one, two, three, etc., ${ }^{2,3}$

Critically, however, whereas English does not feature a direct competitor to singular forms, multiple languages, including Central Slovenian, which we study here, have not only singular and plural forms, but also dual morphology, which is commonly analyzed as morphological marking specialized for reference to doubleton sets, similar to the numeral two (Corbett, 2000; specifically for Slovenian see Kopitar, 1808; Toporišič, 2000; Marušič \& Žaucer, to appear). ${ }^{4}$ Recent studies find that children as young as 2 and 3 years of age begin to produce and comprehend the dual form in Slovenian, and in Saudi Arabic (Almoammer et al., 2013; Marušič et al., 2016). For example, when children learning dual dialects are shown a set of two objects, they often spontaneously label the set using a dual noun phrase (Marušič et al., 2016), and almost always produce dual agreement if they label the set with the numeral two. Similarly, when asked to give a set of objects, children often give exactly two items when the request features dual morphology, as in (6b):

(6) a. Ali lahko postaviš gumb V posodico?

Q can put.2p.sg button.singular in container

Can you put a button in the container?

b. Ali lahko postaviš gumba v posodico?

Q can put.2p.sg button.dual in container

Can you put buttons-DL in the container?

c. Ali lahko postaviš gumbe v posodico?

Q can put.2p.sg button.plural in container

Can you put buttons in the container?

2 Note that an approach to grammatical number like the one just presented, in which the plural is said to mean "at least one", can only work if the plural gets pragmatically strengthened in the usual cases by the interpretation of the singular. But if the singular is to present a stronger alternative to the plural for sets with the cardinality one, the singular must either be itself pragmatically enriched or have a lexical meaning of "exactly one" (cf. Sauerland, 2003).

3 Note that the same reasoning is applicable also to Slovenian, which we study here. To the question in (ia), one can easily answer with (ib). Similarly, (ii) does not only mean that the utterer does not have multiple children, but rather that they have no children at all (cf. Marti, 2020).

(i) a. Ali imaš otroke?

$\mathrm{Q}$ have child.plural

'Do you have children?'

b. Ja, imam eno hčerko.

yes, have one daughter.singular

(ii)

'Yes, I have a daughter.'

Nimam otrok.

neg-have child.plural

'I do not have children.' = I have no children at all.

4 Slovenian dialects differ substantially in the extent of the presence of dual morphology. See Jakop (2008) for a detailed study of the presence of dual across dialects. We use Central Slovenian as it is one of the dialects that uses dual morphology substantially (cf. Marušič et al., 2016 for a comprehensive map of the distribution and the extent of dual marking in Slovenian dialects). 
These previous findings suggest that children learning dual languages acquire a morphological form - the dual - that could potentially act as a pragmatic competitor to the singular. Unlike the plural, which is not associated with any particular set size, dual expressions are associated with doubleton sets, much like the singular is associated with singletons. In this sense, the dual offers a type of successor to the singular much like two is a successor to one, and may therefore be more likely to act as a pragmatic competitor and source of exhaustification. On the hypothesis that children acquire an exact meaning for the numeral one by virtue of first learning a stronger competitor, like two (Barner \& Bachrach, 2010), we might therefore expect that children exposed to a dual language would initially assign singular forms an "at least” interpretation, before they learn the semantics of the dual, at which time they should treat the singular as exact. Such a pattern would provide evidence that children strengthen the singular once they have acquired dual morphology.

Related to this prediction, previous studies find that English-speaking children exhibit a singleton interpretation of singular nouns early in acquisition - i.e., associating it with sets of 1 but that they don't pragmatically exhaustify the singular at adult-like levels until much later, to exclude reference to sets of 2 or more. First, children begin to produce singular and plural forms sometime between 20- and 24-months of age (Barner, Thalwitz, Wood, Yang, \& Carey, 2007; Brown, 1973; Cazden, 1968; Ferenz \& Prasada, 2002; Mervis \& Johnson, 1991). Second, studies using preferential looking find that when children hear a noun phrase presented with singular agreement, they're significantly more likely to look at a singleton set vs. a set containing more than one item, compared to when they hear the noun phrase presented with plural agreement (Kouider, Halberda, Wood, \& Carey, 2006; see also Arias-Trejo, Cantrell, Smith, \& Alva Canto, 2014; Davies, Rattanasone, \& Demuth, 2017; Davies, Rattanasone, Schembri, \& Demuth, 2019; (Fernald, Pinto, Swingley, Weinberg, \& McRoberts, 1998; Swingley, Pinto, \& Fernald, 1998, 1999; Golinkoff, Hirsh-Pasek, Gordon, \& Cauley, 1987). Third, when children are told that, e.g., “some trucks” are hidden in a box, they continue to search after finding 1 truck, but don’t continue searching as much if they were originally told that there was "a truck" hidden in the box (Wood, Kouider, \& Carey, 2009). Each of these past studies provide evidence that the core semantic meanings of singular and plural forms are acquired relatively early. However, and most relevant to the present study, although English-speaking 2-year-olds typically give just 1 object when asked to give, e.g., "a banana”, if they are shown 2 bananas in a container and asked, "Is there a banana in the container?" they respond “yes” over $75 \%$ of the time (unlike adults, who systematically say no in the same task; Barner, Chow, \& Yang, 2009; for similar findings, see Tieu, Bill, Romoli, \& Crain, in press). Likewise, and compatible with accounts of the singularplural described above, many such children also accept the plural when shown only 1 item despite spontaneously giving more than 1 when asked for a plural set. In sum, while previous studies suggest that very young English-speaking children spontaneously associate the singular form with singleton sets, they also show that children readily accept singular expressions when more than 1 object is referred to, compatible with a failure to compute a scalar implicature.

In the present study, we explored the question of whether children might converge on exact meanings of linguistic expressions via scalar implicature by investigating the acquisition of 
singular/dual/plural morphology. In particular, in Experiment 1 we asked whether the acquisition of dual morphology impacts the interpretation of the singular by testing how Slovenian children who have acquired the dual interpret singular forms and comparing them to English-speaking children. Also, in Experiment 2 we tested younger Slovenian children at an age when we expect their knowledge of the dual to be weaker. We hypothesized that if children use the dual form to pragmatically strengthen the singular - resulting in an exact interpretation - then two specific results should be predicted. First, Slovenian children who have acquired dual morphology should interpret singular forms differently from English-speaking children, who are not exposed to the dual; in particular, only Slovenian children should treat the singular as exact. Note that, because all previous theories of singular-plural morphology treat the singular as lexicaly non-exact, this result is only expected if children strengthen the singular pragmatically, and therefore is not predicted by accounts which argue that preschool children are unable to derive exact meanings via implicature. Second, we predicted that younger Slovenian children who are still learning the dual should be less likely than older Slovenian children to treat the singular as exact, despite nevertheless exhibiting knowledge of its core semantic meaning (i.e., its association with singleton sets). In particular, we expected that these children would prefer to give singleton sets when asked to give a singular amount, but would also not object to the use of singular forms to describe larger sets, compatible with a failure to compute scalar implicature. Evidence that children begin by acquiring a weak singleton meaning for singular forms and only treat the singular as exact after acquiring the dual would provide particularly strong evidence that children can derive exact meanings via implicature early in language acquisition. Consequently, these studies assessed the general plausibility of the idea that verbal numerals might get their exact meanings in language acquisition via pragmatic inference - i.e., a process of exhaustifying a weaker expression, like one, with a stronger scalar alternative, like two.

\section{Experiment 1}

The first experiment tested Slovenian children who we expected to have relative mastery of both the singular and the dual forms (based on previous studies), and compared these children to a group of age-matched English-speaking children, to test whether acquiring a dual form might impact children's interpretation of the singular form. In particular, Experiment 1 had two main goals: (1) to replicate previous work showing that English-speaking preschoolers don't exhaustify their interpretation of the singular, and (2) to ask whether Slovenian-speaking preschoolers (who have access to the dual) exhaustify their interpretation of the singular. In addition to these questions, we also asked whether learning the dual affects how Slovenian children interpret the plural (e.g., by restricting it to sets greater than 2).

\subsection{Method}

Participants. We tested 46 Slovenian-speaking children aged 53-71 months $(M=63.3)$, and 50 English-speaking children aged 48-71 months $(M=57.9)$. An additional 3 children were tested but not included in the Slovenian sample because their first language was not Central Slovenian, and 6 were tested but not included in our dataset because they were outside of our target age 
range. All Slovenian-speaking children were recruited in public preschools or kindergartens in the city of Ljubljana, Central Slovenia. All English-speaking children were recruited in San Diego, CA. Parents/caregivers of all participants gave written consent. Apart from their language background, no additional data about children were collected. Recruitment and experimental procedures for both experiments were approved by the UCSD Human Research Protection Program and by the Ethical Committee of the Faculty of Arts, University of Ljubljana.

Stimuli and Procedure. Each child was tested in a session that lasted between 10 and 15 minutes. Three tasks were used: (1) Give-a-Number, (2) Acceptability Judgment, and (3) GiveMorphology. Each child received the tasks in the above order.

Give-a-Number. This task was adapted from Wynn (1992). Stimuli consisted of a plastic plate and a set of ten identical colorful buttons. To begin, the experimenter said, "Here are some buttons and here is a plate. I want you to put what I need on the plate. Are you ready?” Then, the experimenter asked the child to put a certain number of buttons onto the plate, starting from the number one (e.g., "Can you put one on the plate? Put one on the plate and tell me when you're all done.”). ${ }^{5}$ When a child gave $\mathrm{N}$ buttons (e.g., 1) correctly, the answer was recorded; when they failed, the experimenter asked them to count and give them a chance to correct their response (e.g., "Is that one? Can you count and make sure?”). After the child confirmed their answer or made a correction, the experimenter recorded the final number of buttons the child put onto the plate. The experimenter proceeded and requested $\mathrm{N}+1$ buttons (e.g., 2), after which the number of buttons requested was pseudo-randomized. We tested comprehension of labels for 1, 2, 3, 4, 5, 6,8 , and 10 three times each. The inclusion of labels for smaller numbers (i.e., 1-3) allowed us to identify one-knowers, two-knowers, and three-knowers, which are typically found in studies of number word learning. The larger numbers were included to assess whether children could use counting to accurately provide larger sets. To reduce the duration of the task not all numbers between 4-10 were tested (i.e., 7 and 9 were excluded), in keeping with our labs' practices. Per Wynn's (1992) criteria, a child was called an N-knower (e.g., a two-knower) if they successfully gave $\mathrm{N}$ buttons (e.g., two) on 2 out of 3 trials, but failed to give $\mathrm{N}+1$ buttons (e.g., three) on 2 out of 3 trials. In addition, for at least $2 / 3$ of the trials on which children gave $N$, they did so in response to a request for $N$ (and not for some other number). Children who met these same criteria for sets of 4 and 5 were credited with being so-called Cardinal Principle knowers (CPknowers), who generally are able to count to give larger sets.

Acceptability Judgment. This task was adapted from Skordos and Papafragou (2016). Children were first introduced to a puppet named Didi on a computer. The experimenter then told children that Didi sometimes says things well and sometimes she makes mistakes, and that the child's job is to decide whether Didi responded appropriately or not. For example, English children heard the following (for Slovenian text, see the SOM):

Experimenter: "Didi always says what she sees on the screen. But you know what, Didi sometimes says it well and sometimes she makes a mistake. Will you help me and tell me when Didi says it well and when she makes a mistake?”

5 One or two were used instead of "one button" or "two buttons" to avoid providing morphological cues on the noun (i.e., button vs. buttons) that might signal whether the question refers to singleton or non-singleton sets. 


\section{Didi: "I see red shoes."}

Experimenter: "Did Didi say it well or did she make a mistake?"

Children received four familiarization trials, two with Didi correctly describing an image and two with Didi making mistakes. For example, on one familiarization trial, children saw four pairs of blue shoes on the screen and heard a recording of Didi saying, "I see red shoes", and were asked to judge whether Didi said it well or made a mistake (see Supplementary materials for the remaining three familiarization trials). Children gave verbal responses and the experimenter recorded their answers by pressing 1 or 0 on the keyboard. If children responded incorrectly after the first question, the experimenter emphasized the features of the image described by the puppet, and prompted them to try once more, giving them feedback and correcting their answer if necessary.

After the four familiarization trials, children moved on to the test trials. First, they were introduced to a new creature, Trom (Slovenian) / Blicket (English). On each test trial, children saw an image of Trom/Blicket with some items beneath it, and then heard a recording of Didi describing the scene (e.g., on a trial where Trom/Blicket had two buttons, Didi might say, “Trom/Blicket has one/two/four buttons”). Children were then asked to judge whether Didi said it well or made a mistake.

Object-type (buttons, balloons, and cups) and quantity (1, 2, or 4 items) varied withinsubjects. Following the methods of Skordos and Papafragou (2016), object type was blocked such that all trials depicting a certain object type (e.g., buttons) were clustered together. Trials were clustered in this way to emphasize numerical contrasts between trials, rather than contrasts between types of things. This was done to maximize the likelihood of implicature in this task, and critically was done both for English and Slovenian participants such that it could not explain any differences between groups.

Participants were randomly assigned to one of two between-subjects conditions: The Morphology condition, in which Didi always used the singular, dual (for Slovenian only), or plural (e.g., “Trom has buttons”), or the Number condition, in which Didi always used number words including the words for 1, 2, and 4 (e.g., “Trom has four buttons”). The Number condition was administered to establish that children could provide exact interpretations of expressions in this task, and to permit comparison with the Morphology condition. Examples of stimuli used in both conditions are presented in Table 1 (see SOM for the complete protocol with Slovenian stimuli). In Slovenian, there were thus 27 trials in both Number and Morphology condition, while in English, there were 27 trials in the Number condition, and 18 in the Morphology condition (since English has no dual morphology).

Give-Morphology. This task was used to measure children's knowledge of singular/dual (Slovenian only)/plural morphology and whether they spontaneously associate singular forms with singular sets, dual forms with doubleton sets, and plural forms with pluralities. Unlike the Acceptability Judgment Task, it did not assess whether children would reject these forms for alternative set sizes. Therefore, it was a test of whether children differentiated the forms compatible with having acquired a core semantic meaning - but not a test of implicature. Stimuli consisted of the same plastic plate from the Give-a-Number task, and a set of ten identical 
buttons. To begin, the experimenter presented the buttons and the plate to the child and said, "Here are some buttons and here is a plate. I want you to put what I need on the plate. Are you ready?” Then, the experimenter asked the child to put either a button-singular, button-dual (Slovenian only), or buttons-plural on to the plate. The experimenter always started with the plural form, after which the singular, dual, and plural forms varied in a pseudo-randomised order. In Slovenian, each trial type (singular, dual, plural) was tested four times for a total of 12 trials per child, and in English, singular and plural forms were each tested three times for a total of 6 trials per child (see SOM for the complete protocol with Slovenian stimuli).

Table 1: (English) Auditory and visual stimuli for trials in both conditions.

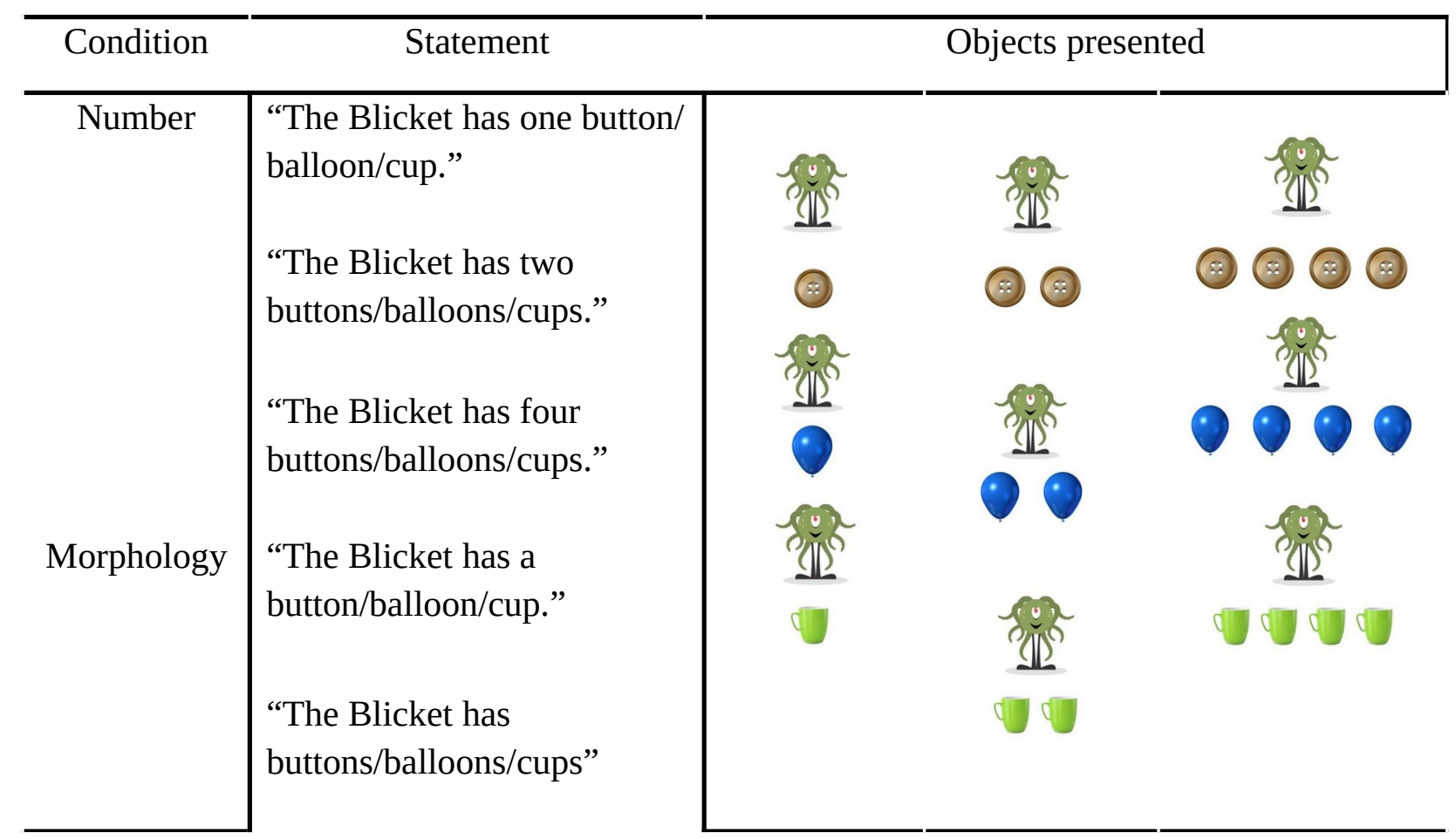




\subsection{Results}

Data Preparation and Analyses. All analyses were conducted using the lme4 package in R (Bates, Maechler, Bolker, \& Walker, 2014). We conducted binomial logit analyses predicting binary performance ( 1 vs. 0 ) from our predictors, with a random effect of subject (1| subj). Whenever model convergence was not an issue, we included a random slope of condition (condition|subject).

Give-a-Number Task. Overall, participants in both groups were overwhelmingly CPknowers (English: 94\%; Slovenian: 98\%) and therefore had robust knowledge of all number words tested in the Acceptability Judgment task.

\subsubsection{English-Speaking Children.}

We first asked whether our English dataset was compatible with previous work (e.g., Barner et al., 2009) regarding children's interpretation of singular and plural forms.

Give-Morphology Task. Data from the Give-Morphology task are presented in Figure 1. Consistent with previous work, we found that when the singular was used to request items on the Give-Morphology task, children successfully gave 1 item $78.67 \%$ of the time, significantly more often than when the request was in the plural form $(2.67 \% ; B=15.87, S E=2.92, p<.0001)$.

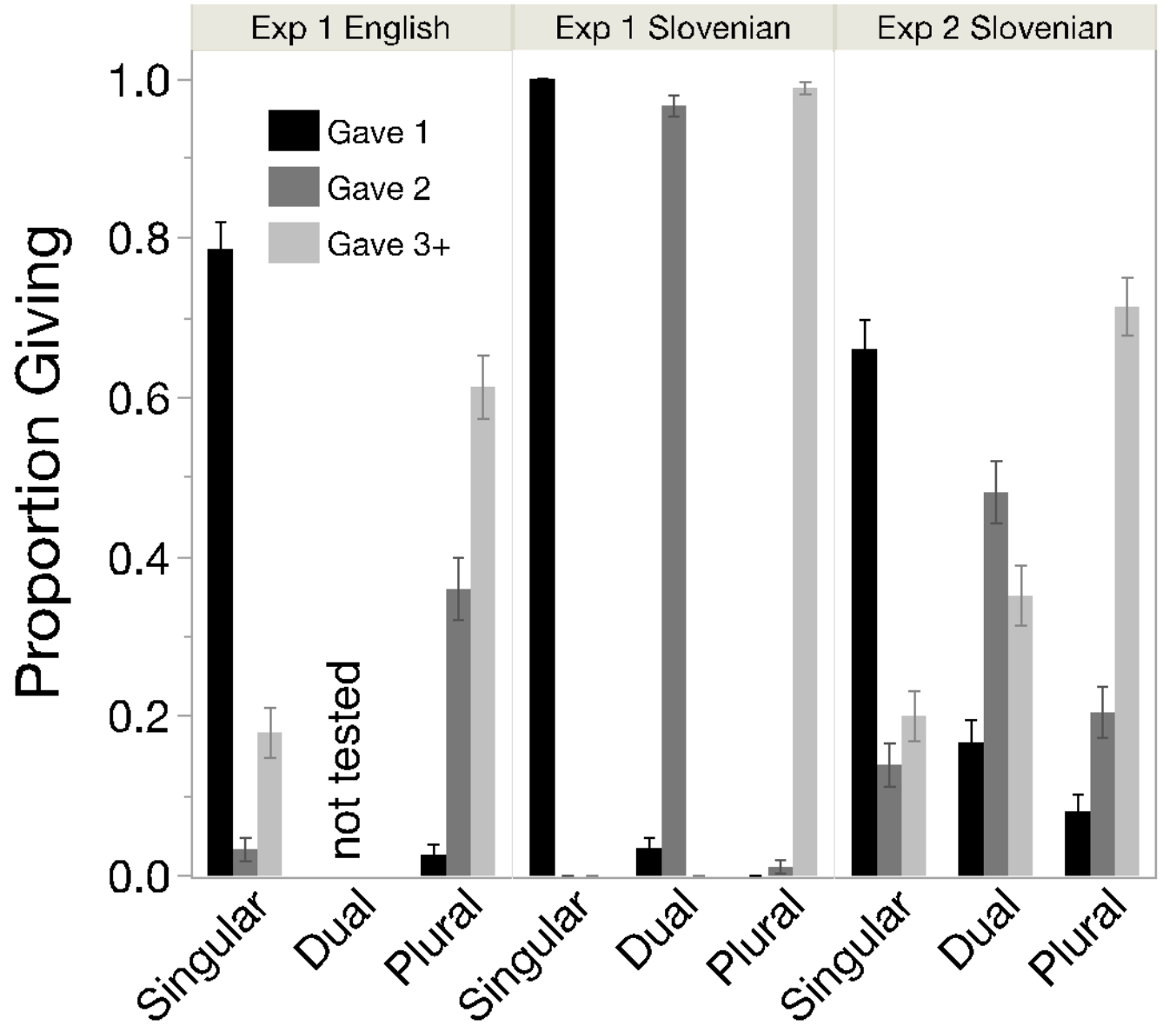

Figure 1. Give-M Performance for Exps 1 and 2. Error bars are SEM.

Acceptability Judgment Task. While data from the Give-Morphology task establish that children most strongly associate the singular with singleton sets, it does not address whether they 
judge singular expressions to be unacceptable descriptions of larger sets. Specifically, although it's possible that children give one item in response to singular requests because they believe no other response is possible (because of exhautification), it's also possible that they do so because it's their preferred response, despite believing that other answers are possible. Given this, the Give-M results can establish that children have a different meaning for singular, dual, and plural forms, but can't decide whether they exhaustify these forms via implicature - e.g., to infer that the singular is restricted to sets of one. We tested this question using data from the Acceptability Judgment task. Data are presented in Figure 2. When presented with a singleton set, Englishspeaking children generally accepted both the singular (67\%) and the word one (88.9\%), though they were more likely to accept one than the singular $(B=-1.77, S E=.78, z=-2.26, p=.024$; see Fig. 2). Though children didn't always accept one and the singular for singleton sets, most children did, compatible with expectations and previous literature. Also, consistent with previous reports, when considering non-singleton sets, English-speaking children were much more likely to accept the singular (35.9\%) than one (3.5\%; $B=-1.83, S E=.75, z=2.4, p=.015$; Fig. 2). This difference was significantly larger than the difference in children's acceptance of the singular and one for sets of one item, resulting in a significant interaction of morphology (singular vs. one) and set size (one object vs. more than one object; $B=4.63, S E=.76, p$ $<.0001)$. Overall, this pattern of results is compatible with previous reports that English-speaking children are more likely to assign an exact interpretation to the verbal numeral one than they are to singular expressions. In other words, when describing sets larger than one, English-speaking children find the singular to be a much more acceptable description than the numeral one.

Finally, in English (unlike Slovenian, reported below), we did not predict differences in rates of plural acceptance for sets of two vs. sets of four, and, in fact, did not find differences (Plural $_{\mathrm{Two}}$ : 66.7\%; Plural ${ }_{\text {Four: }}$ 62.8\%; $B=.32, \mathrm{SE}=.46, \mathrm{z}=.69, p=.49$ ). Note that, compatible with previous reports (e.g., Barner et al., 2009), English-speaking children often accepted the plural for singleton sets. This is compatible with accounts of the singular-plural distinction like those discussed in the introduction, which argue that the plural is semantically compatible with singleton sets, much like the singular is compatible with sets of more than one, and that each type of expression is subject to pragmatic enrichment via exhaustification (e.g., see Spector, 2007).

\subsubsection{Slovenian-Speaking Children}

We next assessed results from Slovenian-speaking children.

Give-Morphology Task: First, to confirm that Slovenian-speaking children comprehended the singular, plural, and dual forms, we analyzed their responses in the GiveMorphology task. When the singular was used to request items on the Give-Morphology task, children gave exactly one item $100 \%$ of the time, while they only did so for requests in the dual form $3.4 \%$ of the time and never did so for requests for the plural form. On dual trials, children gave two items $96.6 \%$ of the time, while they never did so for singular trials and only did so 
$1.1 \%$ of the time for plural trials $\left(B=-7.81, S E=.82, z=-9.48, p<.0001^{6}\right.$, see Figure 1$)$. Finally, for the plural children gave $3+$ items $98.9 \%$ of the time, whereas they never did so for singular or dual trials.

Acceptability Judgment Task. We next analyzed performance on the Acceptability Judgment task. When presented with a singleton set, Slovenian preschoolers (unlike Englishspeaking children) accepted the singular and one equally often $(B=-119.1, S E=219.6, z=-.54$, $p=.59$; note that across both conditions, children only said "no" five times total). Also, Slovenian children accepted the singular $97 \%$ of the time and accepted one $100 \%$ of the time when presented with singleton sets, which was more consistent than English children in each case. Critically, also unlike English-speaking children, when considering non-singleton sets, Slovenian children were equally unlikely to accept the singular and one $(B=1.69, S E=2.34, z$ $=.72, p=.47)$. Specifically, when presented with sets of two items, children accepted the singular $7.2 \%$ of the time, and accepted one $1.4 \%$ of the time. Similarly, when presented with four items, children accepted the singular $4.3 \%$ of the time, and accepted one $0 \%$ of the time (see Figure 2). In other words, unlike English-speaking children, Slovenian-speaking children categorically judged that the singular was unacceptable for describing sets larger than one.

Next, we asked about Slovenian children's interpretation of the plural. In Slovenian, if the dual competes with the plural, then this should predict lower rates of acceptance of the plural for sets of two than for sets of four. This is precisely what we found (Plural ${ }_{\text {Two }}$ : 27.5\%; Plural $_{\text {Four: }}$ : 91.3\%; $B=-3.97, S E=.70, z=-5.65, p<.0001)$. Recall that in English we found no difference in acceptance of the plural for sets of 2 vs. sets of 4 . This cross-linguistic difference suggests that the presence of the dual in Slovenian restricts children's interpretation of the plural to sets of three or more. Thus, the dual appears to both place an upper bound on the singular, and a lower bound on the plural in Slovenian. Finally, we asked whether Slovenian-speaking children were more likely to accept sets of two for the dual than they were to accept sets of four and found that

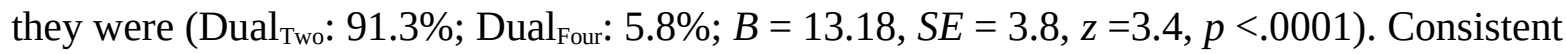
with the view that these children already had access to an adult-like interpretation for the dual (where we assume that adult-like interpretation of the dual is essentially the same as that of the word for 2, see Introduction), they were no more likely to accept the dual for sets of one (Dual $\left.{ }_{\text {One: }} 2.9 \%\right)$ than for sets of four $(B=-.92, S E=1.02, z=-.91, p=.37$ ). 

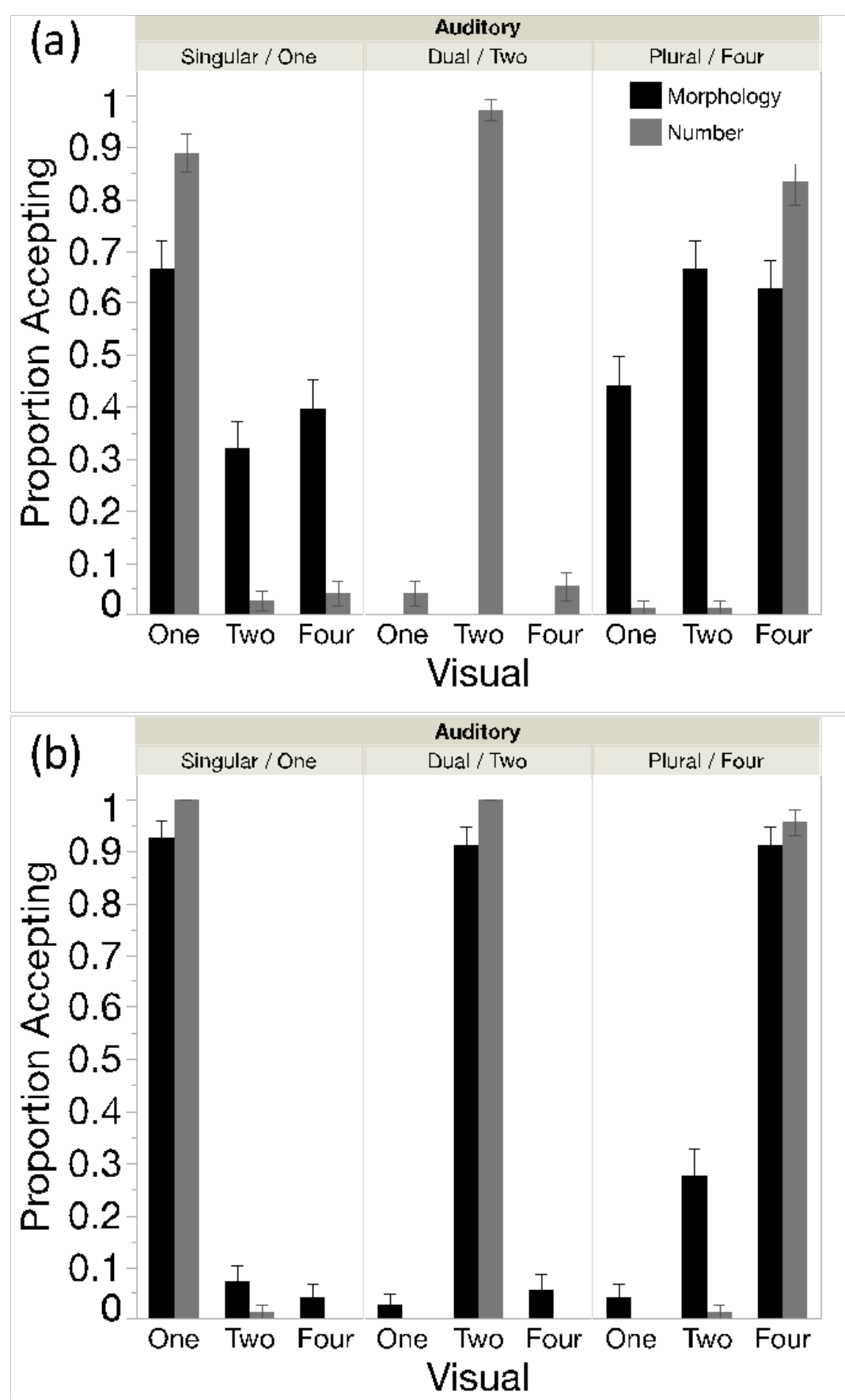

Figure 2. Performance on the Acceptability Judgment task. Black bars indicate performance in the Morphology condition (note that no English-speaking children heard dual morphology, and therefore bars for the dual are absent for figure 2a), while gray bars indicate performance on the Number condition. X-axis indicates visual set size; panels indicate language group: (a) is English, (b) is Slovenian. Error bars are SEM. 


\subsection{Discussion}

Experiment 1 had two main goals: (1) to replicate previous work showing that Englishspeaking preschoolers don't exhaustify their interpretation of the singular, and (2) to ask whether Slovenian-speaking preschoolers (who have access to the dual) exhaustify their interpretation of the singular. In addition, we also asked whether learning the dual changes how Slovenian children interpret the plural (e.g., restricting it to sets of 3 or more).

As in previous work, we found that while English-speaking children frequently provide one object in response to a singular request - compatible with having acquired its core semantic meaning - they nevertheless fail to treat the singular as exact, and also frequently accept it as a description of sets of two or more objects. In contrast, we found that Slovenian-speaking preschoolers who comprehend the dual appear to exhaustify their interpretation of the singular, and also restrict their use of the plural to sets of 3 or more. Most important, unlike Englishspeaking children, Slovenian children accepted singular expressions for sets of one but almost never for larger sets. These findings are consistent with the hypothesis that children can exhaustify the singular to derive an exact meaning, by drawing on knowledge of dual morphology.

While these data are compatible with the hypothesis that knowledge of the dual leads children to exhaustify the singular, they might also be due to other differences between English and Slovenian. For example, one possibility, though not present in the semantic literature on the singular-plural distinction, is that the singular form in dual languages is semantically exact, and therefore is assigned a lexically exact meaning beginning in language acquisition. Although such a view would pose various challenges to explaining how adult speakers of dual languages interpret the singular, we nevertheless sought stronger evidence that it is knowledge of the dual, per se, that explains the difference between how English- and Slovenian-speaking children interpret the singular.

To do this, we conducted Experiment 2, in which we tested 2- and 3-year-old Slovenianspeaking children who had not yet mastered the dual, to test whether dual knowledge was related to strengthening of the singular. We predicted that if the exact interpretation of the singular arises via pragmatic exhaustification, then Slovenian-speaking children who have not mastered the dual should not treat the singular as exact. Specifically, like older English-speaking children, these children should exhibit knowledge of the singular and associate it with singleton sets (as tested by the Give-M task) but also accept the singular form for larger sets in the Acceptability Judgment task. Alternatively, if the exact interpretation of the singular from Experiment 1 is due to some other, non-pragmatic factor (e.g., the meaning of the singular form is different in Slovenian, relative to English), then children who have not yet mastered the dual should nevertheless interpret the singular as exact.

\section{Experiment 2}

Here, we asked how Slovenian-speaking children who have not yet acquired a dual form interpret singular and plural forms. If an exact interpretation of the singular depends on knowledge of the dual, then we should expect younger Slovenian children who lack knowledge 
of the dual to accept singular expressions as descriptions of larger sets. Note that in Experiment 2 we did not test English-speaking children. This is because Experiment 1 established that even older 4- and 5-year-old English-speaking children fail to treat the singular as exact, meaning that data from younger participants would provide little additional information. Instead, we focused on whether Slovenian-speaking children treated the singular as exact, and whether it differed from their interpretation of the word for 1.

\subsection{Method}

Participants. We tested 56 Slovenian-speaking children aged 24-43 months $(M=30.84$ months). An additional four children were tested but not included because their first language was not Slovenian, 18 were tested but not included in our dataset because they failed to complete all required tasks, and two were tested but were excluded for being under age two. As in Experiment 1, Slovenian-speaking children were recruited in public preschools/daycares in Ljubljana. Parents/caregivers provided consent. Apart from their language background, no additional data about children were collected.

Stimuli and Procedure. Tasks, materials, and methods were identical to those reported in Experiment 1, with two differences: in the Give-a-Number task, younger children were only tested with the numbers 1,2 , and 3. In the Give-Morphology task, each morphological form was tested three times for a total of nine trials per child. ${ }^{7}$

\subsection{Results}

Data Preparation and Analyses. To analyze these data, we intended to adopt the analytic approach of Experiment 1, beginning with regression models. However, as we describe below, in some cases these analyses encountered problems of convergence, possibly due to ceiling/floor effects in some conditions, which generated patterns of significance that did not always clearly relate to the patterns of mean differences found in the descriptive statistics. For this reason, we conducted additional post hoc analyses using non-parametric pairwise tests (Wilcoxon signed rank tests), and we report those results as well. ${ }^{8}$ We use the sum of these descriptive and inferential statistics to reach the conclusions described below.

Preliminary Results. A total of 16 participants were non-knowers, 10 were 1-knowers, 19 were 2-knowers, 10 were 3-knowers, and one was a 4-knower. This replicates previously reported findings that 2-knowers are frequent among young Slovenian children exposed to a dual dialect (Almoammer et al., 2013; Marušič et al., 2016). Note that because we used an abbreviated version of Give-N, it is possible that a subset of the 3-knowers may have actually been 4+ knowers. This, however, is not critical to analyses in this experiment, since knower level

7 Eleven of the younger children were initially tested with the version of the Give- $\mathrm{N}$ task described in Experiment 1 ; none were CP-knowers. We then decided to run a shorter version of Give-N for the remaining children in order to make sessions less onerous for children, given that they are younger and less willing to sit for long testing sessions. The same 11 younger children were also tested with the longer version of the Give-Morphology task (four repetitions of each morphological number), after which the shorter version with nine trials was adopted. 8 Note that when we conducted identical post-hoc Wilcoxon tests in Exp. 2, all results aligned with the reported regressions in that experiment. 
information was collected mainly to establish whether children had acquired meanings for one and two.

Give-Morphology task. We first assessed young Slovenian children's interpretation of the singular, plural, and dual forms in the Give-Morphology task. When the singular was used to request items on the Give-Morphology task, children gave one most of the time (65.3\%). Although this was less often than older Slovenian children in Experiment $1,{ }^{9}$ they nevertheless gave one object significantly more often for the singular than for the dual $(15.6 \% ; B=4.07, S E=$ $.49, z=8.37, p<.0001$, see Figure 1$)$ or plural form $(9.1 \% ; B=5.28, S E=.67, z=7.92, p$ $<.0001$ ). On dual trials, children gave two items $48.03 \%$ of the time, significantly more often than for singular trials $(13.2 \% ; B=-2.65, S E=.37, z=-7.1, p<.0001)$ or plural trials $(19.5 \% ; B$ $=-2.24, S E=.37, z=-6.05, p<.0001)$. Finally, for the plural children gave $3+$ items $71.4 \%$ of the time, significantly more often than for singular trials $(21.4 \% ; B=7.61, S E=.70, z=10.92$, $p<.0001$ ) or dual trials (36.4\%; $B=3.27, S E=.46, z=7.14, p<.0001)$. These data suggest that knowledge of singular, dual, and plural forms are emerging but still incomplete in children of this age.

Acceptability Judgment task. We next examined performance on the Acceptability Judgment task. When presented with a singleton set, young Slovenian children accepted the singular (94.6\%) as often as they accepted one (97.1\%; $B=-.17, S E=.93, z=-.18, p=.85$, see Figure 3). Critically, when considering sets of two or four, young Slovenian-speakers did not appear to exhaustify their interpretation of the singular, at least not to the same degree as one. They accepted singular expressions for sets of two and four significantly more often (Sets of two: 75.3\%; Sets of four: 69\%) than they accepted one (Sets of two: $40 \%$; Sets of four: $44.4 \%$; $B=$ $1.77, S E=.59, z=2.99, p=.003) .{ }^{10}$

We next asked about competition between the dual and the plural. Here, our results differed depending on analytic approach, and we therefore do not reach strong conclusions. We first asked whether participants were less likely to accept the plural for sets of two (87.1\%) than for sets of four (96.7\%), which would be evidence of competition between the dual and plural. When using mixed-effects logistic regression, we found evidence of competition $(B=-2.39$, $S E$ $=.97, z=-2.47, p=.013)$, although for post hoc Wilcoxon tests we do not $(p=.08) .{ }^{11}$ Therefore, if there is competition between the forms, the effect is relatively weak, compatible with still emerging knowledge. Next we asked whether participants were more likely to accept the dual for sets of two than for sets of four. Here, we encountered model convergence errors and therefore could not compute regression models. Post hoc Wilcoxon tests found that participants were more likely to accept the dual for sets of two (100\%) than for sets of four $(74.2 \%, p<.0001)$. Finally, both our regression approach and the Wilcoxon test suggested that children were no more likely

9 For the purposes of analyses below, it's important to note that whereas in Experiment 1 almost all children were CP-knowers and all knew at least the word for 1, in Experiment $230 \%$ of children were non-knowers.

10 Note that to parallel our analyses in Experiment 1 we attempted to compute an interaction testing the acceptance of the singular and one for sets of one vs. two/four, but this model failed to converge due to lack of variability in children's responses. We instead present pairwise comparisons.

11 Follow-up analyses that considered only 1+-knowers and 2+-knowers showed the same pattern of results and significance for all reported analyses. 
to accept the dual for sets of one (73.33\%) than for sets of four $(B=-.14, S E=.43, z=.33, p$ $=.74)$. Thus, overall children appeared to prefer the use of the dual with sets of two, but this preference was much weaker compared to older children.

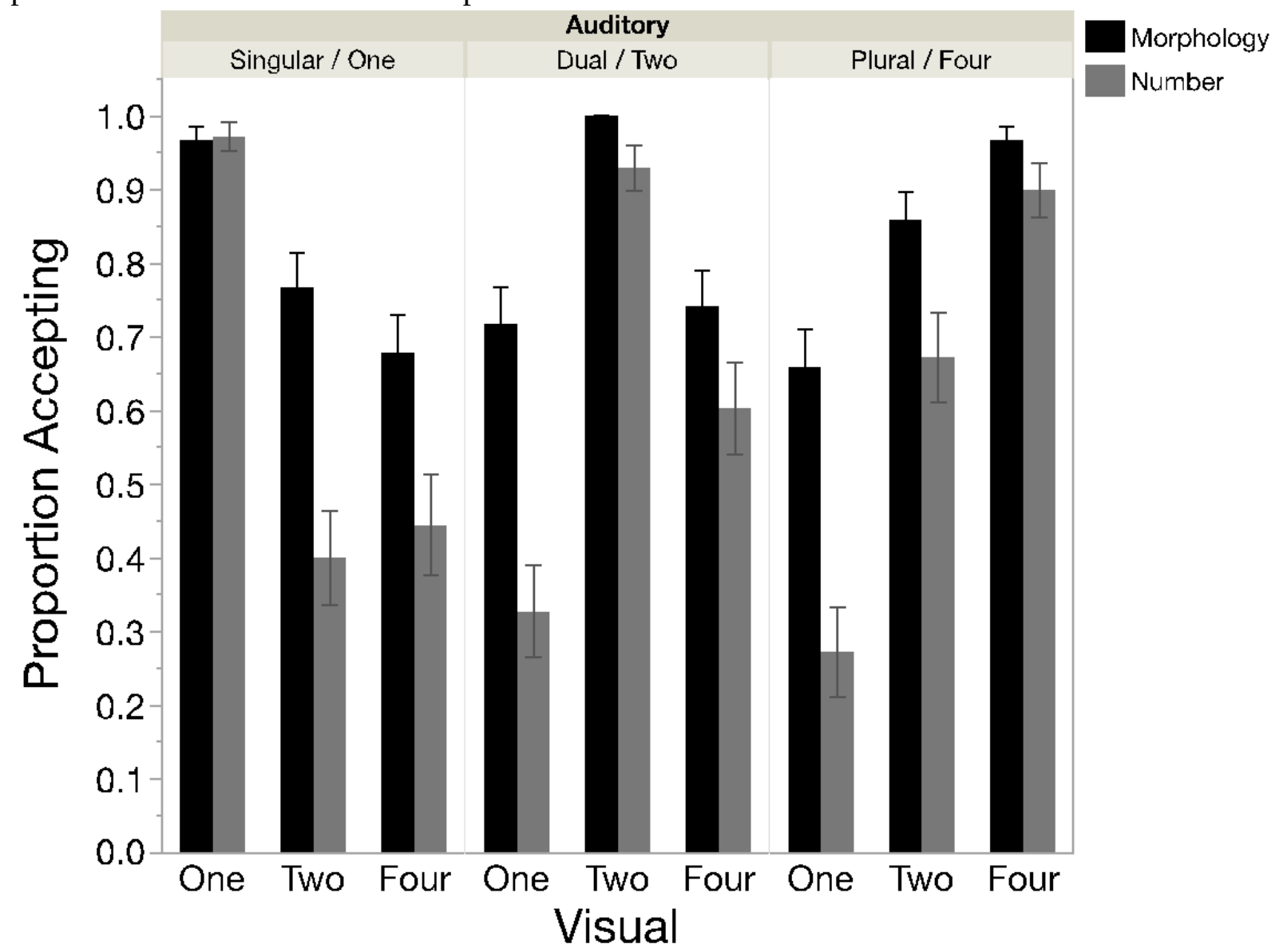

Figure 3. Proportion of young Slovenian-speaking children accepting responses in the Number (gray) and Morphology (black) conditions of the Acceptability Judgment Task. Error bars are SEM.

\subsection{Discussion}

In Experiment 2, we found that 2- and 3-year-old children, who had much weaker knowledge of the dual than older children tested in Experiment 1, were much less likely to exhaustify the singular than the Slovenian word for one. This is not because children lacked a meaning for these expressions, since in the Give-a-Number task most children were at least 1knowers, and in the Give-Morphology task most children gave one object when asked to give a singular amount. Clearly, children associated the singular with sets of one, but simply did not find the singular to be unacceptable when used in the presence of larger sets, compatible with a logical singleton meaning and a failure to compute a scalar implicature.

Together, these findings suggest that Slovenian children begin with a meaning for the singular and plural forms that are similar to those found in English, and that only upon acquiring the dual form do they begin to treat the singular as exact, via processes of exhaustification. Thus, data from Experiment 2 - where children had not yet mastered the dual - suggests that in the 
absence of mastery of the dual, the singular is not exhaustified. This is most consistent with the view that the dual leads to the exhaustification of the singular.

\section{General Discussion}

In the present study, we asked whether pragmatic inference might contribute to the origin of exact linguistic meanings. To do so, we asked whether exhaustification of the singular is more likely in a language that provides an immediate cardinal "successor" in the form of dual morphology. In addition to testing whether singular and plural forms might be exhaustified via pragmatic processes (see Mathieu, 2014; Bale, 2009; Bale et al., 2011; Krifka, 1989; Sauerland, 2003; Sauerland et al., 2005; Spector, 2007; Zweig, 2009), we also explored the general plausibility of the hypothesis that such a mechanism might explain the origin of exact cardinal meanings of words like one and two in the case of number word acquisition (Barner \& Bachrach, 2010). To do this, we tested children acquiring Central Slovenian, which features a three-way scalar distinction - singular-dual-plural - and compared them to US children acquiring English, who learn a binary singular-plural distinction. We reasoned that if the existence of an immediate cardinal successor to the singular - i.e., the dual - enhances exhaustification, then Slovenianspeaking children should be more likely to exhaustify the singular than English-speaking children.

In Experiment 1, we found that unlike age-matched English-speaking children, Slovenian-speaking 4- to 6-year-olds assigned an exact interpretation to both the singular and the Slovenian word for one. They accepted both forms when they were used to refer to singleton sets, but overwhelmingly rejected both when they were used to refer to larger sets (i.e., of two or four). Note that on most previous accounts of the singular-plural distinction, such a treatment of the singular could only arise via scalar implicature since singular forms are generally assumed to have non-exact semantic meanings. Therefore, on such accounts, our data can only be explained by children's use of scalar implicature to generate exact interpretations of singular morphology. Still, one possibility is that singular forms are different in dual languages like Central Slovenian, and are semantically exact, unlike in English. This was addressed by Experiment 2, which found that many younger children had not yet acquired a robust meaning for the dual and also failed to treat singular forms as exact, despite associating the singular with singleton sets. Note that in this regard, the younger Slovenian children tested in Experiment 2 performed much like Englishspeaking children in previous studies (Barner et al., 2009; Tieu et al., in press), readily associating the singular with sets of one (in some cases by as early as 24 months; Kouider et al., 2006; Wood et al., 2009), but also accepting its use for larger sets. Only older Slovenianspeaking children who had mastered the dual also exhaustified their interpretation of the singular. Together, these data suggest that the singular is interpreted differently both developmentally and cross-linguistically as a function of its relevant alternatives, and that the availability of a cardinal successor, in the form of the dual, greatly increases the likelihood that the singular will be interpreted exactly.

Interestingly, Experiment 1 also found that Central Slovenian-speaking children exhaustified the dual to the same degree as the singular, and robustly accepted the dual to refer to 
sets of two, but not to smaller or larger sets. Further, and relatedly, we found some evidence that Slovenian-speaking children of all ages assigned a lower bounded interpretation to the plural (e.g., they accepted the plural to refer to sets of four, but not to sets of two), but that Englishspeaking children did not. As noted in our introduction, and as suggested by our data from English-speaking children in Experiment 1, the existence of a plural does not alone result in reliable strengthening of the singular to an "only one" meaning. ${ }^{12}$ Given this, we might expect that the plural would also not impact how children interpret the dual - and that children might therefore treat the dual as lower bounded. Instead, we found that Slovenian children in Experiment 1 assigned the dual an exact interpretation. One possible explanation of this finding is that both the singular and the plural in Slovenian have qualitatively different types of meanings than in English - i.e., that the singular is inherently upper bounded, and the plural lower bounded. However, as already noted no previous account argues for such an account of either the singular or the plural (Mathieu, 2014; Bale, 2009; Bale et al., 2011; Krifka, 1989; Sauerland, 2003; Sauerland et al., 2005; Spector, 2007; Zweig, 2009, Martí, 2020). Also, our data from Experiment 2 suggest that, absent knowledge of the dual, young Slovenian-speaking children treat the singular and plural much like English children do. Given this, our findings suggest that the dual plays a unique role - different from the role of the plural - in strengthening competing morphological forms, perhaps because it constitutes an immediate cardinal successor to the singular.

An important question not answered by our study is how the dual acquires this meaning. According to one account, proposed by Sauerland (2008), the dual receives only an upper bounded interpretation, i.e., "one or two", and subsequently receives pragmatic strengthening to mean just "two". Against this, we found no difference in the use of the dual for sets of 1 vs. sets of 4 items, which is not consistent with the view that the dual is purely upper bounded. Also, a recent study in adult speakers of Slovenian corroborated this (Marušič, Žaucer, Sudo, \& Nevins, in prep), and found that speakers treat the dual much like the numeral for "two" and generally restrict it to sets of two. On their analysis, the dual is bilaterally strengthened lexically, and permits weakening pragmatically under certain circumstances. Such findings might be taken to suggest that, unlike the singular, the dual is lexically strengthened from the start, and that in acquisition some meanings begin as exact, while others do not. An alternative to this, however, is that the lexical meaning found in adults is acquired by children via pragmatic processes. Note that unlike singular and plural forms, which often take on non-numerical existential or generic readings (see the Introduction), the dual unambiguously denotes doubleton sets in most contexts. Consequently, the dual provides a salient numerical alternative to both the singular and plural forms, which may in turn highlight their respective roles as numerical alternatives to the dual. As noted in the Introduction, there is now substantial evidence that children's ability to compute scalar implicatures is impacted by the relative accessibility of relevant scalar alternatives, which can be impacted either by making alternatives contextually available, or by making the speaker's

12 Note that as explained in footnote 3 and argued by Martí (2020), adult Central Slovenian behaves like adult English when it comes to the use of plural, which means that the only difference between Central Slovenian and English is really the existence of the dual. 
intended “Question Under Discussion” (Roberts, 2012) more salient in the conversational context (since, on Roberts' analysis, the QUD is defined as a set of relevant alternatives). Thus, the relative accessibility of the dual as an unambiguous expression of numerical content may impact the entire system of number morphology in a dual language like Central Slovenian.

While our data have important implications for how we understand the role of exhaustification in the interpretation of number morphology, they are also relevant to research on the nature and origin of numeral meanings. As discussed in the Introduction, previous studies have debated both how processes of exhaustification affect number morphology - like the singular/plural distinction - and also whether pragmatic processes might be at play in either the online interpretation of numerals (Bott, Bailey, \& Grodner, 2012; Breheny, Ferguson, \& Katsos, 2013; Degen \& Tanenhaus, 2015, 2016; Huang \& Snedeker, 2009; Panizza, Chierchia, \& Clifton, 2009), or in the acquisition of exact numeral meanings (Barner \& Bachrach, 2010; Huang et al., 2013). Our study provides evidence that the interpretation of singular and plural forms may differ substantially across different languages as a function of the availability of additional competitors, like the dual. This therefore provides an existence proof for the idea that early developing pragmatic abilities - now documented in a variety of different studies - might plausibly result in exhaustification of not only grammatical number, but also perhaps of number word meanings too - e.g., such that a singleton meaning for the word one is strengthened to “exactly one” by virtue of acquiring an immediate successor, two. Also, relevant to our discussion above, even if adult number word meanings and the meaning of the dual are lexically exact, these exact meanings might plausibly be derived via pragmatic processes early in development (Barner \& Bachrach, 2010).

Our study also provides an important demonstration that preschoolers can compute scalar implicatures with different scale types, under the right conditions, particularly when the relevant scalar alternatives are available to them. Not only do children appear to compute implicatures at a relatively young age, but as in studies such as Skordos and Papafragou (2016) they do so in a paradigm that requires them to express "intolerant” statements in an acceptability judgment task (see also Barner et al., 2018). These findings collectively suggest that children's reluctance to compute implicatures early in development is not due to pragmatic tolerance (Katsos \& Bishop, 2011), but instead because they lack access to relevant alternatives that license computation of implicatures. The behavior of the Slovenian children in our experiments suggests that beyond ad hoc scales and quantifiers, where children readily compute implicatures during the preschool years, morphological number should be included in the cases where pragmatically derived meanings are likely within the abilities of young children.

In conclusion, our study of children acquiring Central Slovenian finds evidence that processes of exhaustification may explain the emergence of both upper and lower bounded interpretations of grammatical number morphology. This raises the possibility that other exact forms - like numerals - may also rely on pragmatic processes, at least initially when meanings are first being acquired (if not later in life). 


\section{References}

Almoammer, A., Sullivan, J., Donlan, C., Marušič, F., Žaucer, R., O’Donnell, T., \& Barner, D. (2013). Grammatical morphology as a source of early number word meanings. Proceedings of the National Academy of Sciences, PNAS, 110(46), 18448-18453. Arias-Trejo, N., Cantrell, L. M., Smith, L. B., \& Alva Canto, E. A. (2014). Early comprehension of the Spanish plural. Journal of Child Language, 41, 1356-1372.

Bale, A. (2009). Yet more evidence for the emptiness of plurality. In Proceedings of the 38th meeting of the north east linguistic society (NELS 38) (pp. 75-88). Graduate Linguistic Students’ Association, University of Massachussetts.

Bale, A., Gagnon, M., \& Khanjian, H. (2011). On the relationship between morphological and semantic markedness: The case of plural morphology. Morphology, 21(2), 197-221.

Barner, D., \& Bachrach, A. (2010). Inference and exact numerical representation in early language development. Cognitive Psychology, 60, 40-62.

Barner, D., Chow, K., \& Yang, S. (2009). Finding one's meaning: A test of the relation between quantifiers and integers in language development. Cognitive Psychology, 58(2), 195219.

Barner, D., Brooks, N., \& Bale, A. (2011). Accessing the unsaid: The role of scalar alternatives in children's pragmatic inference. Cognition, 118(1), 84-93.

Barner, D., Hochstein, L., Rubenson, M., \& Bale, A. (2018). Four-year-old children compute scalar implicatures in absence of epistemic reasoning. In K. Syrett, \& A. Arunachalam (Eds.), Semantics in Acquisition (pp. 326-349). John Benjamins.

Barner, D., Thalwitz, D., Wood, J., Yang, S. J., \& Carey, S. (2007). On the relation between the acquisition of singular-plural morpho-syntax and the conceptual distinction between one and more than one. Developmental science, 10(3), 365-373.

Bates, D., Maechler, M., Bolker, B., \& Walker, S. (2014). Ime4: Linear mixed-effects models using Eigen and S4. R package version 1.0-6. http://CRAN.R-project.org/package=lme4

Bott, L., Bailey, T. M., \& Grodner, D. (2012). Distinguishing speed from accuracy in scalar implicatures. Journal of Memory and Language, 66(1), 123-142.

Breheny, R. (2008). A new look at the semantics and pragmatics of numerically quantified noun phrases. Journal of Semantics, 25(2), 93-139.

Breheny, R., Ferguson, H. J., \& Katsos, N. (2013). Investigating the timecourse of accessing conversational implicatures during incremental sentence interpretation. Language and Cognitive Processes, 28(4), 443-467.

Brown, R. (1973). A first language: The early stages. Cambridge, MA: Harvard University Press. Carey, S. (2009). The origin of concepts. Oxford University Press.

Carston, R. (1988). Implicature, explicature and truth-theoretic semantics. In R. Kempson (Ed.), Mental Representations: the Interface between Language and Reality (pp. 155-181). Cambridge University Press. 
Carston, R. (1998). Informativeness, relevance and scalar implicature. In R. Carston, \& S. Uchida (Eds.), Relevance Theory. Applications and Implications (pp. 179-238). John Benjamins.

Cazden, C. (1968). The acquisition of noun and verb inflections. Child Development, 39, 433448.

Chierchia, G., Crain, S., Guasti, M. T., Gualmini, A., \& Meroni, L. (2001). The acquisition of disjunction: Evidence for a grammatical view of scalar implicatures. In Proceedings of the 25th Boston University conference on language development (pp. 157-168).

Chierchia, G., Fox, D., \& Spector, B. (2012). Scalar implicature as a grammatical phenomenon. In K. von Heusinger, C. Maienborn, \& P. Portner (Eds.), Semantics: An International Handbook of Natural Language Meaning. Volume 3 (pp. 2297-2331). De Gruyter.

Corbett, G. G. (2000). Number. Cambridge University Press.

Davies, B., Rattanasone, N. X., \& Demuth, K. (2017). Two-year-olds' sensitivity to inflectional plural morphology: Allomorphic effects. Language Learning and Development, 13, 38-53.

Davies, B., Rattanasone, N. X., Schembri, T., \& Demuth, K. (2019). Preschoolers' developing comprehension of the plural: The effects of number and allomorphic variation. Journal of Experimental Child Psychology, 185, 95-108.

Degen, J., \& Tanenhaus, M. K. (2016). Availability of alternatives and the processing of scalar implicatures: A visual world eye-tracking study. Cognitive science, 40(1), 172-201.

Degen, J., \& Tanenhaus, M. K. (2015). Processing scalar implicature: A constraint-based approach. Cognitive science, 39(4), 667-710.

Ferenz, K. S., \& Prasada, S. (2002). Singular or plural? Children's knowledge of the factors that determine the appropriate form of the count nouns. Journal of Child Language, 29, 49-70.

Fernald, A., Pinto, J. P., Swingley, D.,Weinberg, A., \& McRoberts, G. (1998). Rapid gains in speed of verbal processing by infants in the second year. Psychological Science, 9, 228-231.

Foppolo, F., Guasti, M. T., \& Chierchia, G. (2012). Scalar Implicatures in Child Language: Give Children a Chance. Language Learning and Development, 8, 365-394.

Fox, D. (2007). Free choice and the theory of scalar implicatures. In U. Sauerland, \& P. Stateva (Eds.), Presupposition and Implicature in Compositional Semantics (pp. 71-120). Palgrave Macmillan.

Fox, D. \& Hackl, M. (2007) The universal density of measurement. Linguistics and Philosophy, 29, 537-586

Geurts, B. (2006). Take 'five'. The meaning and use of a number word. In S. Vogeleer, \& L. Tasmowski (Eds.), Non-definiteness and Plurality (pp. 311-329). John Benjamins.

Golinkoff, R., Hirsh-Pasek, K., Gordon, L., \& Cauley, K. (1987). The eyes have it: Lexical and word order comprehension in a new context. Journal of Child Language, 14, 23-45.

Gunderson, E. A., Spaepen, E., \& Levine, S. C. (2015). Approximate number word knowledge before the cardinal principle. Journal of Experimental Child Psychology, 130, 35-55. 
Horn, L. (1972). The semantics of logical operators in English [Unpublished doctoral dissertation]. University of California, Los Angeles.

Huang, Y. T., \& Snedeker, J. (2009). Online interpretation of scalar quantifiers: Insight into the semantics-pragmatics interface. Cognitive psychology, 58(3), 376-415.

Huang, Y. T., Spelke, E., \& Snedeker, J. (2013). What exactly do numbers mean?. Language Learning and Development, 9(2), 105-129.

Jakop, T. (2008). The dual in Slovene dialects. Universitätsverlag Brockmeyer.

Katsos, N., \& Bishop, D. V. (2011). Pragmatic tolerance: Implications for the acquisition of informativeness and implicature. Cognition, 120(1), 67-81.

Koenig, J.-P. (1991). Scalar predicates and negation: punctual semantics and interval interpretations. In L. M. Dobrin, L. Nichols, \& R. M. Rodriguez (Eds.), Papers from the 27th Regional Meeting of the Chicago Linguistics Society (CLS27), Part 2: Parasession on Negation (pp. 140-155). Chicago Linguistics Society.

Kopitar, J. (1808). Grammatik der Slavischen Sprache in Krain, Kaernten und Steyermark [Grammar of the Slavic Language of Carniola, Carinthia and Stiria]. bey Wilhelm Heinrich Korn.

Krifka, M. (1989). Nominal reference, temporal constitution and quantification in event semantics. In R. Bartsch, J. van Benthem, \& P. van Emde Boas (Eds.), Semantics and contextual expression (pp. 75-115). Foris.

Kouider, S., Halberda, J., Wood, J., \& Carey, S. (2006). Acquisition of English Number Marking: The Singular-Plural Distinction. Language Learning and Development, 2(1), 1-25.

Levinson, S. C. (2000). Presumptive meanings. MIT Press.

Long, M., Shukla, V., \& Rubio-Fernandez, P. (2020). The Development of Simile Comprehension: From Comparison to Scalar Implicature. PsyArXiv. February 27, 2020. doi:10.31234/osf.io/utwec.

Martí, L. (2020). Inclusive Plurals and the Theory of Number. Linguistic Inquiry, 51(1), 37-74.

Marušič, F., Žaucer, R., Plesničar, V., Razboršek, T., Sullivan, J., \& Barner, D. (2016). Does grammatical structure speed number word learning? Evidence from learners of dual and non-dual dialects of Slovenian. PLoS ONE, 11(8), e0159208.

Marušič, F., \& Žaucer, R. (to appear). Case study: Slovenian Dual. In P. Cabredo Hofherr, \& J. Doetjes (Eds.), The Oxford Handbook of Grammatical Number. Oxford University Press.

Marušič, L., Žaucer, R., Sudo, Y., \& Nevins, A. (in prep). An Experimental Investigation into the Semantics and Pragmatics of the Slovenian Dual. LingBuzz. https://ling.auf.net/lingbuzz/005390. August 29, 2020.

Mathieu, E. (2014). Many a plural. In A. Aguilar-Guevara, B. Le Bruyn, \& J. Zwarts (Eds.), Weak Referentiality (pp. 157-182). John Benjamins.

Noveck, I. A. (2001). When children are more logical than adults: experimental investigations of scalar implicature. Cognition, 78, 165-188. 
Pagliarini, E., Bill, C., Romoli, J., Tieu, L., \& Crain, S. (2018). On children's variable success with scalar inferences: Insights from disjunction in the scope of a universal quantifier. Cognition, 178, 178-192. doi:10.1016/j.cognition.2018.04.020

Panizza, D., Chierchia, G., \& Clifton Jr, C. (2009). On the role of entailment patterns and scalar implicatures in the processing of numerals. Journal of memory and language, 61(4), 503-518.

Papafragou, A., \& Musolino, J. (2003). Scalar implicatures: experiments at the semanticspragmatics interface. Cognition, 86(3), 253-282.

Papafragou, A., \& Tantalou, N. (2004) Children’s Computation of Implicatures. Language Acquisition, 12(1), 71-82.

Van Rooij, R., \& Schulz, K. (2004). Exhaustive interpretation of complex sentences. Journal of logic, language and information, 13(4), 491-519.

Roberts, C. (2012). Information structure: Towards an integrated formal theory of pragmatics. Semantics and Pragmatics, 5(6), 1-69. doi:10.3765/sp.5.6

Saddock, J. (1984). Whither radical pragmatics? In D. Schiffrin (Ed.), Meaning, Form and Use in Context (pp. 139-149). Georgetown University Press.

Sauerland, U. (2003). A new semantics for number. In R. Young, \& Y. Zhou (Eds.), Proceedings of SALT 13 (pp. 258-275). Cornell University.

Sauerland, U. (2008). On the semantic markedness of $\Phi$-features. In D. Harbour, D. Adger, \& S. Bejar (Eds.), Ф-Features (pp. 57-82). Oxford University Press.

Sauerland, U., Andersen, J., \& Yatsushiro, K. (2005). The plural is semantically unmarked. In S. Kepser, \& M. Reis (Eds.), Linguistic Evidence. Empirical, Theoretical and Computational Perspectives (pp. 413-434). Mouton de Gruyter.

Scharten, R. (1997). Exhaustive interpretation: a discourse-semantic account [Unpublished doctoral dissertation]. Katholieke Universiteit Nijmegen.

Singh, R., Wexler, K., Astle-Rahim, A., Kamawar, D., \& Fox, D. (2016). Children interpret disjunction as conjunction: Consequences for theories of implicature and child development. Natural Language Semantics, 24(4), 305-352.

Skordos, D., \& Papafragou, A. (2016). Children's derivation of scalar implicatures: alternatives and relevance. Cognition, 153, 6-18.

Spector, B. (2007). Aspects of the pragmatics of plural morphology: On higher-order implicatures. In U. Sauerland, \& P. Stateva (Eds.), Presupposition and Implicature in Compositional Semantics (pp. 243-281). Palgrave Macmillan.

Spector, B. (2013). Bare numerals and scalar implicatures. Language and Linguistics Compass, 7(5), 273-294.

Stiller, A. J., Goodman, N. D., \& Frank, M. C. (2015). Ad-hoc Implicature in Preschool Children. Language Learning and Development, 11, 176-190.

Swingley, D., Pinto, J. P., \& Fernald, A. (1998). Assessing the speed and accuracy of word recognition in infants. In C. Rovee-Collier, L. P. Lipsitt, \& H. Hayne (Eds.), Advances in infancy research (257-277). Stamford, CT: Ablex. 
Swingley, D., Pinto, J. P., \& Fernald, A. (1999). Continuous processing in word recognition at 24 months. Cognition, 71, 73-108.

Tieu, L., Bill, C., Romoli, J. \& Crain, S. (in press). Testing theories of plural meanings. Cognition, 205. DOI: 10.1016/j.cognition.2020.104307

Toporišič, J. (2000). Slovenska Slovnica [Slovenian grammar] (4th edition). Založba Obzorja.

Wagner, K., Chu, J., \& Barner, D. (2019). Do children’s number words begin noisy? Developmental Science, 22(1), e12752.

Wood, J. N., Kouider, S., \& Carey, S. (2009). Acquisition of singular-plural morphology. Developmental Psychology, 45(1), 202-206.

Wynn, K. (1990). Children's understanding of counting. Cognition, 36(2), 155-193.

Wynn, K. (1992). Children's acquisition of the number words and the counting system. Cognitive Psychology, 24, 220-251.

Zweig, E. (2009). Number-neutral bare plurals and the multiplicity implicature. Linguistics and Philosophy, 32(4), 353-407. 


\section{Do children derive exact meanings pragmatically? Evidence from a dual morphology language SOM - Supplementary Materials}

Below we provide stimuli and protocols used in our experiments.

\section{Experiment 1.1}

\subsection{Task (1) Give-a-Number}

Adapted from Wynn (1992). Stimuli consisted of a plastic plate/ a piece of paper with a red circle and a set of ten identical colorful buttons. To begin, the experimenter said:

- English: "Today we're going to play a game with some things I have! Look at my things! [show toys]. I'm going to ask you to give me what I need, and I want you to put what I need in the red circle. When you're finished, say "all done". Ready??";

- Slovenian: "Zdaj se bova igrala/igrali novo igrico. Tu so igrače in tu je rdeč krog. Rada bi, da igrače prestaviš v krog. Pozorno poslušaj." (Translation: "Now we are going to play a new game. Here are some toys and here is a red circle. I'd like you to put toys in the circle. Listen carefully.")

Then, the experimenter asked the child to put a certain number of buttons onto the plate:

- English: "Can you put $X$ in the red circle. Put $X$ in the red circle. Tell me when you're all done!" [X is a number]

- Slovenian: "Ali lahko prestaviš $X v$ rdeč krog? Prestavi X v rdeč krog in povej, ko boš zaključil/a." [X is a number]

If the child stopped but didn't say "All Done", the experimetner asked if they're all done, trying to get them to say "All Done". Once they are done, the experimenter asked them to verify they are sure:

- English: "Is that X?"

- Slovenian: "Je to $X$ ?"

If they answered "Yes" and they put the right number, their answer was record. If they answered "No", all pieces were put back and the trial restarted. If they answered "Yes" and they put the wrong number, the experimenter said:

- English: "Can you count and make sure?"

- Slovenian: "Ali lahko prešteješ in se prepričaš?"

and after they counted said:

- English: "so, is that $X$ ?"

- Slovenian: "Je to $X ?$ ?"

If they said "No"/"Ne", all pieces were put back and the trial restarted. If they said "Yes"/"Ja", their (incorrect) answer was recorded.

The sequence of tested numbers was set in the two Slovenian experiments. In Experiment 1, where older Slovenian kids were tested numbers 1-10 were tested in this sequence (each of the numbers $1,2,3,4,5,8,10$ was tested three times): $1-2-4-8-5-3-10-3-10-4-$ $1-5-2-8-10-2-1-5-4-8-3$. In Experiment 2, where younger Slovenian kids were tested, only numbers 1,2 , and 3 were tested in this order (each appering three times): $2-1-3$ 
$-1-3-2-3-1-2$. English- speakeing kids were tested with numbers: 1, 2, 3, 4, 5, 6, 8, 10 in the following fashion. The experimenter started with "1". If the child got a trial right, the experimenter moved to $\mathrm{X}+1$ (e.g., 2); If they got it wrong, the experimenter moved to $\mathrm{X}-1$. When they completed the sequence of numbers, the number of buttons requested was pseudorandomized. Each number $(1,2,3,4,5,6,8,10)$ was tested three times.

\subsection{Task (2) Acceptability Judgment}

Acceptability Judgment task was adapted from Skordos and Papafragou (2016). Children were first introduced to a puppet named Didi on a computer. The experimenter then told children that Didi sometimes says things well and sometimes she makes mistakes, and that the child's job is to decide whether Didi responded appropriately or not:

- English: "Didi always says what she sees on the screen. But you know what, Didi sometimes says it well and sometimes she makes a mistake. Will you help me and tell me when Didi says it well and when she makes a mistake?"

- Slovenian: "Didi vedno pove, kaj vidi na ekranu. Ampak veš kaj? Diti se včasih zmoti. Didi včasih pove prav, včasih pa narobe. Mi boš ti pomagal/-a in mi povedal/-a, kdaj Didi prav reče in kdaj narobe?"

Children received four familiarization trials, two with Didi correctly describing an image and two with Didi making mistakes. The four familiarization trials were:

1. Children saw four pairs of blue shoes on the screen and heard a recording of Didi saying:

- English:

- Didi: "I see red shoes."

- Experimenter: "Did Didi say it well or did she make a mistake?"

- Slovenian:

- Didi: "Vidim rdeče čevlje."

- Experimenter: "Je Didi prav povedala ali se je zmotila?"

2. Children saw four different balls on the screen and heard a recording of Didi saying:

- English:

- Didi: "I see balls."

- Experimenter: "Did Didi say it well or did she make a mistake?"

- Slovenian:

- Didi: "Vidim žoge."

- Experimenter: "Je Didi prav povedala ali se je zmotila?"

3. Children saw a shoal of fish on the screen and heard a recording of Didi saying:

- English:

- Didi: "I see many fish."

- Experimenter: "Did Didi say it well or did she make a mistake?"

- Slovenian:

- Didi: "Vidim veliko ribic."

- Experimenter: "Je Didi prav povedala ali se je zmotila?"

4. Children saw three umbrellas on the screen and heard a recording of Didi saying:

- English:

- Didi: "I see an umbrella." 
- Experimenter: "Did Didi say it well or did she make a mistake?"

\section{- Slovenian:}

- Didi: "Vidim en dežnik."

- Experimenter: "Je Didi prav povedala ali se je zmotila?"

Children gave verbal responses and the experimenter recorded their answers by pressing 1 or 0 on the keyboard. If children responded incorrectly after the first question, the experimenter emphasized the features of the image described by the puppet, and prompted them to try once more, giving them feedback and correcting their answer if necessary.

After the four familiarization trials, children moved on to the test trials. First, they were introduced to a new creature, Trom (Slovenian) / Blicket (English). On each test trial, children saw an image of Trom/Blicket with some items beneath it, and then heard a recording of Didi describing the scene. E.g., on a trial where Trom/Blicket had two buttons, Didi might say:

- English: "Blicket has one/two/four buttons."

- Slovenian: "Trom ima en/dva/štiri gumbe."

Children were then asked to judge whether Didi said it well or made a mistake.

Object-type (buttons, balloons, and cups) and quantity (1, 2, or 4 items) varied within-subjects. Participants were randomly assigned to one of two between-subjects conditions: The Morphology condition, in which Didi always used the singular, dual (for Slovenian only), or plural (e.g., "Trom has buttons"), or the Number condition, in which Didi always used number words including the words for 1, 2, and 4 (e.g., "Trom has four buttons"). Table 1 gives the auditory and visual stimuli used in the Slovenian experiment.

Table 1: (Slovenian) Auditory and visual stimuli for trials in both conditions.

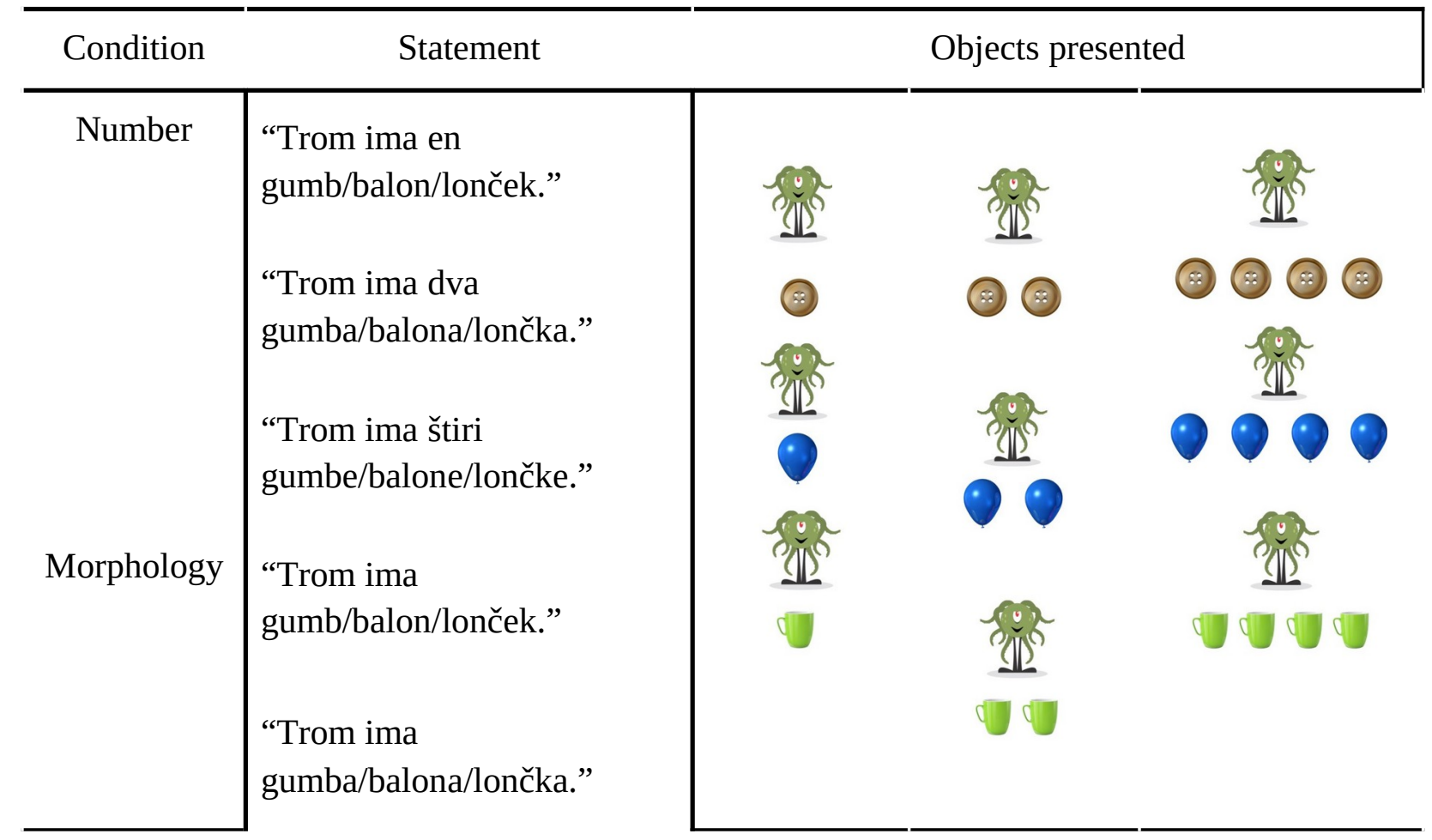


"Trom ima

gumbe/balone/lončke.”

\subsection{Task (3) Give-Morphology}

Give-Morphology. This task was used to measure children's knowledge of singular/dual (Slovenian only)/plural morphology. Stimuli consisted of the same piece of paper with a red circle from the Give-a-Number task, and a set of ten identical buttons. To begin, the experimenter presented the buttons and the red circle to the child:

- English: "Today we're going to play a new game with some things I have! Look at my things! [show toys]. I'm going to ask you to give me what I need, and I want you to put what I need [in the red circle/on the plate/in the bowl]. When you're finished, say "all done". Ready?"

- Slovenian: "Zdaj se bova igrala/igrali novo igrico. Tu so igrače in tu je rdeč krog. Rad/rada bi, da igrače prestaviš v krog. Pozorno poslušaj." (Translation: "Now we are going to play a new game. Here are some toys and here is a red circle. I'd like you to put toys in the circle. Listen carefully.")

Then, the experimenter asked the child to put either a button-singular, button-dual (Slovenian only), or buttons-plural on to the plate.

- English: "Can you put button/buttons in the bowl?"

- Slovenian: "Ali lahko prestaviš gumb / gumba / gumbe v rdeč krog?"

The experimenter always started with the plural form, after which the singular, dual, and plural forms varied in a pseudo-randomised order. In Slovenian, each trial type (singular, dual, plural) was tested four times for a total of 12 trials per child, and in English, singular and plural forms were each tested three times for a total of 6 trials per child. 